\title{
Antibiotic susceptibility profiles of some Vibrio strains isolated from wastewater final effluents in a rural community of the Eastern Cape Province of South Africa
}

\author{
Anthony I Okoh* and Etinosa O Igbinosa
}

\begin{abstract}
Background: To evaluate the antibiogram and antibiotic resistance genes of some Vibrio strains isolated from wastewater final effluents in a rural community of South Africa. V. vulnificus (18), V. metschnikovii (3), V. fluvialis (19) and V. parahaemolyticus (12) strains were isolated from final effluents of a wastewater treatment plant (WWTP) located in a rural community of South Africa. The disk diffusion method was used for the characterization of the antibiogram of the isolates. Polymerase chain reaction (PCR) was employed to evaluate the presence of established antibiotic resistance genes using specific primer sets.

Results: The Vibrio strains showed the typical multidrug-resistance phenotype of an SXT element. They were resistant to sulfamethoxazole (Sul), trimethoprim (Tmp), cotrimoxazole (Cot), chloramphenicol (Chl), streptomycin (Str), ampicillin (Amp), tetracycline (Tet) nalidixic acid (Nal), and gentamicin (Gen). The antibiotic resistance genes detected includes $d f r 18$ and $d f r A 1$ for trimethoprim; floR, tetA, strB, sul2 for chloramphenicol, tetracycline, streptomycin and sulfamethoxazole respectively. Some of these genes were only recently described from clinical isolates, demonstrating genetic exchange between clinical and environmental Vibrio species.

Conclusions: These results demonstrate that final effluents from wastewater treatment plants are potential reservoirs of various antibiotics resistance genes. Moreover, detection of resistance genes in Vibrio strains obtained from the wastewater final effluents suggests that these resistance determinants might be further disseminated in habitats downstream of the sewage plant, thus constituting a serious health risk to the communities reliant on the receiving waterbodies.
\end{abstract}

\section{Background}

Antibiotic-resistant bacteria have been found in a surprisingly diverse range of environments, including human clinics, animal husbandry, orchards, aquaculture, food, sewage, chlorinated, and unchlorinated water supplies [1]. Antimicrobial resistance has become a major medical and public health problem as it has direct links with disease management [2]; and while antibiotics such as tetracycline, doxycycline, norfloxacin, ciprofloxacin and streptomycin may be used as an adjunct in rehydra-

\footnotetext{
*Correspondence: aokoh@ufh.ac.za

${ }^{1}$ Applied and Environmental Microbiology Research Group (AEMREG),

Department of Biochemistry and Microbiology, University of Fort Hare, Private Bag X1314, Alice 5700, South Africa

Full list of author information is available at the end of the article
}

tion therapy and are critical in the treatment of septicemia patient [3-5], resistance to many of these drugs in many pathogens including Vibrio pathogens such as $V$. vulnificus, $V$. cholerae, $V$. fluvialis and V. parahaemolyticus [6-8] have been documented.

Report of drug-resistant $V$. cholerae strains are appearing with increasing frequency [9]. Emergence of microbial resistance to multiple drugs is a serious clinical problem in the treatment and containment of the cholera-like diarrhoea, as reflected by the increase in the fatality rate from $1 \%$ to $5.3 \%$ after the emergence of drugresistance strains in Guinea-Bissau during the cholera epidemic of 1996-1997 [10]. A genetic element, termed SXT element, which has properties similar to those of the conjugative transposons, was found to carry genes encod- 
ing resistance to sulfamethoxazole, trimethoprim and streptomycin in V. cholerae $\mathrm{O} 139$ and $\mathrm{O} 1$ strains isolated in India, but was not present in O1 strain obtained in 1994 from Rwandan refugees in Goma, Zaire [11]. Previous report showed that gene cassettes contained in class 1 integrons were distributed among different $V$. cholerae O-serotypes of mainly clinical origin in Thailand [12]. Also, the presence and transfer of SXT element and resistance gene in class 1 integrons have been studied in South Africa [13], which reported for the first time the presence of SXT element in $V$. cholerae $\mathrm{O} 1$ clinical isolates in Africa [13].

As the SXT genetic element plays a role in the acquisition of antibiotic resistance, it is important to also assess the presence of sul2 (encoding sulfamethoxazole resistance), dfrA1 (O1-specific trimethoprim resistance), $d f r 18$ (O139 and non-O139 trimethoprim resistance) $[14,15]$, and $\operatorname{str} B$ (streptomycin B resistance) gene in $V$. cholerae strains [16-18]. Waldor et al. [1996] identified in $V$. cholerae $\mathrm{O} 1$ and $\mathrm{O} 139$ an approximately $62 \mathrm{~kb}$ selftransmissible, chromosomally integrating genetic element, which was found to contain genes encoding resistance to sulphonamides, trimethoprim and streptomycin [11]. However, the antibiotic susceptibilities of organisms fluctuate spatially and temporally [19]. These susceptibilities have to be examined in order to better understand the organisms' epidemiological features [19].

To the best of our knowledge, no antibiotic resistance gene profile has been investigated in Vibrio species isolated from wastewater final effluents in the rural communities of South Africa, a country currently facing increasing pressure of water pollution from both domestic sewage and industrial wastewater, thus posing a threat to the public health of humans and ecological diversity of marine animals. As part of our ongoing surveillance study on aquatic microbial pathogens, we isolated some Vibrio pathogens [20], and in this paper, we report the antibiotic susceptibility patterns of the Vibrio isolates as well as the distribution of antibiotic resistance genes in the isolates.

\section{Results and Discussion}

\section{Physicochemical analysis of final effluent quality}

In our previous study [21] we reported some physicochemical parameters from the final effluents of a wastewater treatment facility (Table 1). Considerably high concentration of COD, nitrate, and orthophosphate were reported in the study [21]. The quality of the final effluent was consequently evaluated by other standards as reported in $[21,22]$. The final effluents qualities were not compliant to recommended standards for turbidity, COD, nitrate and orthophosphate (Table 1). This disqualifies the effluents for use in domestic activities and suggests that discharging such effluents into receiving watersheds could support eutrophication, with its attendant negative consequence [23].

\section{Antibiogram profile}

The susceptibilities of $V$. vulnificus (18 strains); V. parahaemolyticus (12 strains); V. fluvialis (19 strains) and $V$. metschnikovii (3 strains) to 21 different antibiotics by were examined. All the 52 isolates of Vibrio species were resistant to ampicillin and sulfamethoxazole, and sensitive to imipenem, meropenem and norfloxacin. Vibrio fluvialis showed $100 \%, 90 \%, 70 \%$ and $80 \%$ resistances to trimethoprim, penicillin, cotrimoxazole and streptomycin, respectively, and $92 \%, 82 \% 90 \%$ and $100 \%$ of cephalothin resistances were exhibited by $V$. vulnificus, $V$. parahaemolyticus, $V$ fluvialis and $V$. metschnikovii respectively. The results reveal the high individual and multiple antibiotics resistance among the test Vibrio strains (Additional file 1). Previous studies have shown that streptomycin, rifampicin, kanamycin, tetracycline, polymyxin B were active against Vibrio species [24], but this was at variance with our findings where we observed resistances to streptomycin, tetracycline and polymyxin B in our Vibrio isolates. In this study, resistance to ampicillin was observed in all our Vibrio strains in difference to other studies that have been reported [25,26], but corroborated by the findings of French and coworker [27] who reported similar antibiotics susceptibility profile for $V$. parahaemolyticus.

An increase in multi-antibiotics resistance bacteria in recent years is worrisome and the presence of resistance genes in bacteria has further aided the transmission and spread of drug resistance among microbial pathogens [28]. Most studies on the antimicrobial susceptibility profiles of Vibrio species focus almost exclusively on clinical and/or food isolates with little information in the literature on those isolated from environmental sources such as treated municipal wastewater effluents. To our knowledge, this is the first study that specifically evaluated the antimicrobial susceptibility profile and detection of multiple antibiotics resistance genes of Vibrio strains isolated from treated municipal wastewater effluent in South Africa.

\section{The antibiotic resistance gene cluster and SXT element of Vibrio species strains}

In an attempt to finding a relationship between the multidrug-resistance phenotypes of $V$. vulnificus, $V$. metschnikovii, V. fluvialis and $V$. parahaemolyticus and the presence of the SXT-like element, polymerase chain reaction experiments were carried out using specific primers for the presence of antibiotic resistance genes and the SXT element (Table 2). To ascertain the contribution of SXT to strain resistance profile, we analysed for the presence of sul2, floR, $d f r 18, s t r B$, and $d f r A 1$, typical clustered 
Table 1: Seasonal and annual mean values of physicochemical qualities from the final effluent.

\begin{tabular}{|c|c|c|c|c|c|c|}
\hline \multirow[t]{2}{*}{ Parameters } & \multicolumn{6}{|c|}{ Final effluent } \\
\hline & Range & Mean \pm SD & Autumn & Summer & Winter & Spring \\
\hline $\mathrm{pH}$ & $5.53-9.38$ & $6.65 \pm 0.97$ & $6.40 \pm 0.29 c$ & $7.03 \pm 1.31^{c}$ & $6.10 \pm 0.58^{D}$ & $6.70 \pm 0.34^{C}$ \\
\hline $\begin{array}{c}\text { Temperature } \\
\left({ }^{\circ} \mathrm{C}\right)\end{array}$ & $13.04-27.21$ & $20.95 \pm 4.37$ & $19.82 \pm 3.01^{\mathrm{A}}$ & $24.73 \pm 2.28^{B}$ & $15.24 \pm 2.00^{A}$ & $20.98 \pm 0.98^{A}$ \\
\hline $\begin{array}{l}\text { Turbidity } \\
\text { (NTU) }\end{array}$ & $1.59-25.5$ & $6.68 \pm 5.73$ & $6.25 \pm 4.86^{C}$ & $9.64 \pm 7.32^{c}$ & $3.81 \pm 0.93^{C}$ & $3.68 \pm 2.24^{D}$ \\
\hline TDS (mg/l) & $121-244$ & $144 \pm 19.76$ & $149.50 \pm 0.54^{A}$ & $133.26 \pm 6.80^{A}$ & $\begin{array}{c}144.77 \pm \\
10.68^{B}\end{array}$ & $\begin{array}{c}168.40 \pm \\
42.48^{\mathrm{B}}\end{array}$ \\
\hline $\mathrm{DO}(\mathrm{mg} / \mathrm{l})$ & $1.16-9.46$ & $5.02 \pm 2$ & $4.15 \pm 0.90^{c}$ & $5.38 \pm 2.73^{A}$ & $4.85 \pm 1.25^{C}$ & $4.96 \pm 1.56^{\mathrm{B}}$ \\
\hline $\operatorname{COD}(\mathrm{mg} / \mathrm{l})$ & $10-975$ & $126 \pm 230.6$ & $46.00 \pm 41.69^{A}$ & $\begin{array}{c}238.00 \pm \\
333.71^{\mathrm{A}}\end{array}$ & $\begin{array}{c}49.00 \pm 26.92^{A} \\
B\end{array}$ & $34.82 \pm 17.98^{B}$ \\
\hline $\mathrm{NO}_{3}^{-}(\mathrm{mg} / \mathrm{l})$ & $4.4-18.8$ & $10.43 \pm 3.8$ & $11.75 \pm 8.14^{A}$ & $8.73 \pm 2.08^{A}$ & $13.10 \pm 0.95^{A}$ & $7.96 \pm 5.22^{\mathrm{A}}$ \\
\hline $\mathrm{NO}_{2}^{-}(\mathrm{mg} / \mathrm{l})$ & $0.03-0.46$ & $0.21 \pm 0.12$ & $0.12 \pm 0.07^{B}$ & $0.19 \pm 0.08^{A B}$ & $0.21 \pm 0.15^{\mathrm{B}}$ & $1.30 \pm 1.85^{\mathrm{A}}$ \\
\hline $\mathrm{PO}_{4}^{3-}(\mathrm{mg} / \mathrm{l})$ & $0.12-4.3$ & $2.02 \pm 1.40$ & $0.33 \pm 0.18^{A}$ & $4.81 \pm 0.58^{A}$ & $2.16 \pm 1.71^{\mathrm{A}}$ & $3.98 \pm 0.13^{A}$ \\
\hline
\end{tabular}

Values are means of triplicates \pm Standard deviations (SD); Means with the same letter are not significantly different $(P>0.005)$. Summer (November to March); autumn (April to May); winter (June to August); spring (September to October)

TDS, Total dissolved solid; DO, Dissolved oxygen; $\mathrm{COD}$, Chemical oxygen demand; $\mathrm{NO}_{3}{ }^{-}$, Nitrate; $\mathrm{NO}_{2}{ }^{-}$, Nitrite; $\mathrm{PO}_{4}{ }^{3-}$, Orthophosphate.

resistance genes, able to discriminate among SXT variant. Results revealed that some $V$. vulnificus, V. metschnikovii, $V$. fluvialis and $V$. parahaemolyticus contained one to six of the antibiotic resistance genes of SXT-like element (Additional file 1). The most abundant strain that harboured most of the antibiotic resistance genes and SXT element is $V$. fluvialis. Strains AL024, AL038, AL054 AL056 and AL009 lack SXT integrase, hence, the entire element. TMP, STR and COT resistance can then be associated with any other mobile element especially the class 1 integrons, already described in Africa, both in $V$. cholerae and $V$. parahaemolyticus. SXT-like element devoid of the resistance cluster could be represented by strain AL016, positive for the integrase but not for the gene cassettes.

To date, there have been no reports on the antibiotic resistance genes in $V$. vulnificus, $V$. metschnikovii, $V$. fluvialis and $V$. parahaemolyticus isolated from wastewater final effluents in rural communities of South Africa. The PCR result showed the presence and prevalence of SXTlike elements (with an amplicon size of $1035 \mathrm{bp}$ ) in the Vibrio strains (Additional file 1). The SXT-like element encodes different types of antibiotic resistance genes, floR (526 bp), sul2 (625 bp), and strB (470 bp), which confer resistance to chloramphenicol $(\mathrm{Chl})$, sulfamethoxazole (Sul), and streptomycin (Str), respectively (Additional file 1). Trimethoprim (Tmp) resistance genes were detected with the amplification of a 372 and 389 bp fragment of $d f r A 1$ and $d f r 18$ (Additional file 1). The molecular analysis of these genes has been previously carried out in $V$. cholerae $\mathrm{O} 1$ and $\mathrm{O} 139$ [18,29].
In this present study, all strains exhibited multiple resistances to five antibiotics. Ramachandran et al. [29] carried a study of 51 strains of $V$. cholerae for detection of antibiotic resistant genes and the SXT element belonging to the serogroups O1, O139, non O1 and non-O139, all strains were found to habour antibiotics resistant gene and showed resistances to ampicillin, furazolidone, nalidixic acid, streptomycin, Trimethoprim - sulfamethoxazole and Trimethoprim. Another study carried out in India between 1997 and 1998 involving a total number of 94 isolates of $V$. cholerae reported that 43 strains belonging to non-O1 and non-O139 serogroups contained plasmids that contributed to the multiple antibiotic resistances and exhibited resistances to ampicillin, neomycin, tetracycline, gentamicin, streptomycin, sulfonamide, furazolidone, and chloramphenicol [30]. Our findings corroborate the earlier work of Ramachandran et al. [29] who reported differences in the antibiotics resistance gene cluster in the SXT-like element in $V$. cholerae $\mathrm{O} 1$ and $\mathrm{O} 139$.

The $d f r 18$ and $d f r A 1$ genes cassettes coding for trimethoprim resistance, found among several of our isolates, have also been detected among the strains isolated in Thailand [10], and India [30]. Similarly, the $\operatorname{str} B$ gene for aminoglycoside resistance (streptomycin) found in our collection have been previously detected by Falbo et al. [17] in Albania and Italy in 1994, and Calcutta, India during the period 1997 to 1998 [30]. Previous uses of antibiotics in the earlier outbreaks may be partly responsible for the extensive increase in antibiotics resistances that we have observed in this study. It is unknown 
Table 2: Sequence of primers used for detection of antibiotics resistance genes and the SXT element.

\begin{tabular}{|c|c|c|c|c|}
\hline Primer & Sequence (5' to 3 ') & Target gene & Amplicon size (bp) & Reference \\
\hline SXT-F & ATGGCGTTATCAGTTAGCTGGC & SXT integrase & 1035 & [16] \\
\hline SXT-R & GCGAAGATCATGCATAGACC & & & \\
\hline SUL2-F & AGGGGGCAGATGTGATCGC & sul2 & 625 & [17] \\
\hline SUL2-B & TGTGCGGATGAAGTCAGCTCC & & & \\
\hline FLOR-F & TTATCTCCCTGTCGTTCCAGCG & floR & 526 & [35] \\
\hline FLOR-2 & CCTATGAGCACACGGGGAGC & & & \\
\hline TMP-F & TGGGTAAGACACTCGTCATGGG & dfr18 & 389 & [17] \\
\hline TMP-B & ACTGCCGTITTCGATAATGTGG & & & \\
\hline TetA-F & GTA ATT CTG AGC ACT GTC GC & TetA & 950 & [36] \\
\hline TetA-R & CTG CCT GGA CAA CAT TGC TT & & & \\
\hline strB-F & GGCACCCATAAGCGTACGCC & strB & 470 & [12] \\
\hline strB-R & TGCCGAGCACGGCGACTACC & & & \\
\hline dfr1-F & CGAAGAATGGAGTTATCGGG & $d f r A 1$ & 372 & [35] \\
\hline dfr1-B & TGCTGGGGATTTCAGGAAAG & & & \\
\hline
\end{tabular}

whether the isolates responsible for earlier and recent epidemics are of clonal origin. The association between the developments of resistance to trimethoprim, cotrimoxazole and streptomycin with large-scale use of antibiotics for the treatment and prophylaxis of cholera is well recognized $[13,31]$. Still, our demonstration of multipledrug resistant non-cholera vibrios isolates showing resistance to all the antibiotics traditionally used to treat cholera is worrisome and could have a direct impact on the treatment of current and future cholera cases in South Africa and other countries to which this isolate may spread. Dalsgaard et al. [13] speculated that recent occasional unusually high mortality rate experienced during cholera outbreaks in some African countries could be associated with multiple-drug resistant $\mathrm{O} 1$ isolates carrying resistance gene located in SXT element.

Our findings thus showed that SXT element bearing drug resistance markers were fairly widely distributed in the Vibrio strains isolated from our study sites. It also revealed the frequency of occurrence of the gene cassettes, floR, tet $A, d f r 18$, strB, $d f r A 1$, and sul2. Given that there are increasingly reports of cholera-like diarrhoea being caused by non-vibrio cholera strains, it is important to monitor the distribution of SXTs in emerging Vibrio species.

\section{Conclusion}

To the best of our knowledge, this is the first study that describes the detection of antibiotics resistance genes known to confer resistances to common classes of antibiotics in a rural community of South Africa. The mobile pool of resistance genes shared by bacteria of the wastewater effluents analyzed even included resistance genes that have only recently been described in clinical isolates, indicating genetic exchange between clinical and environmental bacteria. Further, detection of these newer resistance genes isolated from bacterial inhabitants of wastewater final effluents confirms that these determinants are released into the environment, which subsequently facilitates further dissemination among environmental bacteria. Moreover, it appeared that the wastewater purification processes operating in the wastewater treatment facility under study are not efficient enough to significantly reduce the spectrum of resistance genes that are detectable in the final effluents. PCR can be used effectively to detect antibiotics resistance genes and could be used for the surveillance of the spread of antibiotics resistance in epidemiological and environmental studies.

\section{Methods}

Study site

The Wastewater treatment facility is situated at geographical coordinates of $32^{\circ} 50^{\prime} 36^{\prime \prime} \mathrm{S}, 26^{\circ} 55^{\prime} 00^{\prime \prime} \mathrm{E}$ and approximately $1 \mathrm{~km}$ East of Alice town in the Eastern Cape Province of South Africa. The plant which has a design capacity of $2000 \mathrm{~m}^{3} /$ day receives domestic sewage, some light industrial wastewater as well as run-off water, and treatment is based on the activated sludge system. The final effluent is discharged into the nearby Tyume River.

\section{Isolation and biochemical identification of Vibrio species}

Sample collection methods and treatments of collected samples has been described in our previous work [20]. Aliquots of the plankton free and plankton associated 
samples were inoculated into alkaline peptone water (APW, Pronadisa) and incubated aerobically at $37^{\circ} \mathrm{C}$ for 18-24 h. Turbid cultures were streaked onto thiosulphate citrate bile salts sucrose (TCBS, Pronadisa) agar and incubated at $37^{\circ} \mathrm{C}$ for $24 \mathrm{~h}$. Five to ten isolated colonies per plate were randomly picked from each sample and subsequently subcultured on fresh TCBS agar plates. The pure isolates were then subjected to Gram staining and oxidase test, and only Gram-negative, oxidase-positive isolates were selected for biochemical identification using API 20 NE kit. The strips were then read and the final identification was made using API lab plus software (bioMerieux, Marcy l'Etoile, France). Polymerase chain reaction (PCR) was used to confirm the identities of the Vibrio species using the species-specific primers described in our previous study [20].

\section{Bacterial strains}

A total of 52 strains of Vibrio species were included in this study. Of these, 12 were V. parahaemolyticus, 18 were $V$. vulnificus, 19 were $V$. fluvialis and 3 were $V$. metschnikovii. These Vibrio species were isolated in our previous study from the final effluent of a rural wastewater treatment plant in the Eastern Cape Province of South Africa [20]. V. parahaemolyticus strain SABS PM ATCC Vbr 1, V. vulnificus DSM 10143, V. fluvialis DSM 19283 were used as the PCR positive control for sul2, $d f r A 1$, strB, floR, dfr18, tetA, and SXT integrase. All strains were maintained in tryptic soy broth supplemented $30 \%$ glycerol and stored at $-80^{\circ} \mathrm{C}$.

\section{Antibiotic susceptibility test}

Bacterial susceptibilities to the test antibiotics were performed by disk diffusion method using guidelines established by Bauer et al. [32] and recommended by Clinical and Laboratory Standards Institute [33] using commercial antibiotics discs. A total of 21 antibiotic discs (Mast Diagnostics, Merseyside, United Kingdom) which includes ampicillin $(25 \mu \mathrm{g})$, cotrimoxazole $(25 \mu \mathrm{g})$, amikacin $(30 \mu \mathrm{g})$, imipenem $(10 \mu \mathrm{g})$, erythromycin $(15 \mu \mathrm{g})$, meropenem $(10 \mu \mathrm{g})$, streptomycin $(25 \mu \mathrm{g})$, chloramphenicol $(30 \mu \mathrm{g})$, ciprofloxacin $(5 \mu \mathrm{g})$, cephalothin $(30 \mu \mathrm{g})$, nalidixic acid $(30 \mu \mathrm{g})$, tetracycline $(30 \mu \mathrm{g})$, trimethoprim (30 $\mu \mathrm{g})$, norfloxacin $(10 \mu \mathrm{g})$, sulfamethoxazole $(25 \mu \mathrm{g})$, gentamicin $(10 \mu \mathrm{g})$, neomycin $(30 \mu \mathrm{g})$, penicillin $\mathrm{G}$ (10 unit), nitrofurantoin $(200 \mu \mathrm{g})$, polymyxin B (300 units) and cefuroxime $(30 \mu \mathrm{g})$ were employed. Characterization of the resistance or susceptibility profile of the isolates was determined by measuring inhibitory zone and then compared with the interpretative chart to determine the sensitivity of the isolates to the antibiotics.

\section{Isolation of genomic DNA}

Genomic DNA was extracted following a modified scheme of Maugeri et al. [34] Single colonies of Vibrio species strains grown overnight at $37^{\circ} \mathrm{C}$ on TCBS agar plates were picked, suspended in $200 \mu \mathrm{l}$ of sterile Milli-Q PCR grade water (Merck, SA) and the cells were lysed using Dri-block DB.2A (Techne, SA) for $15 \mathrm{~min}$ at $100^{\circ} \mathrm{C}$. The cell debris was removed by centrifugation at 11,000 $\times g$ for 2 min using a MiniSpin micro centrifuge (Merck, $\mathrm{SA})$. The cell lysates $(10 \mu \mathrm{l})$ were used as template in the PCR assays immediately after extraction placed on ice for 5 min or following storage at $-80^{\circ} \mathrm{C}$. Sterile Milli-Q PCR grade water (Merck, SA) was included in each PCR assay as negative control.

\section{PCR amplification assay}

Polymerase chain reaction (PCR) was used to detect antibiotic resistant genes in the Vibrio species using the specific primer pairs and PCR conditions for detection of the SXT integrase, floR, strB, sul2, dfrA18, tetA and dfrA1 are listed in Table 2. All reactions were set in $50 \mu \mathrm{l}$ volume of reaction buffer containing 0.05 unit/ $\mu \mathrm{l} \mathrm{Taq}$ polymerase as directed by the manufacturer (Fermentas Life Sciences). Cycling conditions (Bio-Rad My Cycler ${ }^{\mathrm{m}}$ Thermal Cycler) were as follows; initial denaturation at $94^{\circ} \mathrm{C}$ for $2 \mathrm{~min}$ was followed by 35 cycles of $94^{\circ} \mathrm{C}$ for $1 \mathrm{~min}, 60.5^{\circ} \mathrm{C}$ for $1 \mathrm{~min}$ and $72^{\circ} \mathrm{C}$ for $1 \mathrm{~min}$ with a final extension at $72^{\circ} \mathrm{C}$ for 10 min and cooling to $4^{\circ} \mathrm{C}$. Electrophoresis of amplicons was performed with $1 \%$ agarose gel (Hispanagar, Spain) containing Ethidium Bromide (EtBr) (Merck, SA) with 0.5 $\mathrm{mg} / \mathrm{L}$ for $1 \mathrm{~h}$ at $100 \mathrm{~V}$ in $0.5 \times$ TAE buffer $(40 \mathrm{mM}$ Tris$\mathrm{HCl}, 20 \mathrm{mM}$ Na-acetate, $1 \mathrm{mM}$ EDTA, $\mathrm{pH}$ 8.5) and visualized under an UV transilluminator (BioDoc-It System, UVP Upland, CA 91786, USA).

\section{Additional material}

Additional file 1 Phenotypic and genotypic characterization of Vibrio

strains and their antibiotics resistance genes. Supplemental table.

\section{Authors' contributions}

AIO: conceived of the study, participated in its design, provided technical support and helped to prepare the manuscript. EOI: participated in the study design, carried out the experimental work, and drafted the manuscript. All authors read and approved the final version of the manuscript.

\section{Acknowledgements}

This work was funded by the National Research Foundation (NRF) of South Africa (Grant Ref: FA2006042400043).

\section{Author Details}

Applied and Environmental Microbiology Research Group (AEMREG), Department of Biochemistry and Microbiology, University of Fort Hare, Private Bag X1314, Alice 5700, South Africa

Received: 30 October 2009 Accepted: 14 May 2010

Published: 14 May 2010

\section{References}

1. Chopra I, Roberts M: Tetracycline antibiotics: mode of action, applications, molecular biology, and epidemiology of bacterial resistance. Microbiol Mol Biol Rev 2001, 65:232-260. 
2. Ramamurthy T: Antibiotics Resistance in Vibrio cholerae. In Vibrio cholerae: Genomic and Molecular Biology Edited by: Shah M, Faruque G, Nair B. Horizon Scientific Press. Wiltshire; 2008:195.

3. Lima AA: Tropical diarrhoea: New developments in traveller's diarrhoea. Curr Opin Infect Dis 2001, 14:547-552.

4. Bhattacharya SK: An Evaluation of current cholera treatment. Expert Opin Pharmacother 2003, 4:141-146.

5. Chiang SR, Chuang YC: Vibrio vulnificus infection: Clinical manifestation, pathogenesis and antimicrobial therapy. J Microbiol Infect 2003, 36:81-88.

6. Rowe-Magnus DA, Zouine M, Mazel D: The adaptive Genetic Arsenal of pathogenic Vibrio species: The role of integrons. In the Biology of Vibrios Edited by: Fabiano LT, Brian A, Swings JG. ASM Press, Washington, DC; 2006:95-111.

7. Ahmed AM, Nakagawa T, Arakawa E, Ramamurthy T, Shinoda S, Shimamoto T: New aminoglycoside acetyltransferase gene, aac(3)-Id, in a class 1 integron from a multiresistant strain of Vibrio fluvialis isolated from an infant aged 6 months. J Antimicrob Chemother 2004 53:947-951

8. Ceccarelli D, Salvia AM, Sami J, Cappuccinelli P, Maria M: Colombo New Cluster of Plasmid-Located Class 1 Integrons in Vibrio cholerae $\mathrm{O} 1$ and a dfrA15 Cassette-Containing Integron in Vibrio parahaemolyticus Isolated in Angola. Antimicrob Agents Chemother 2006, 50(7):2493-2499.

9. Mukhopadhyay AK, Garg S, Mitra R, Basu A, Rajendran K, Dutta D, Bhattacharya SK, Shimada T, Takeda T, Takeda Y, Nair GB: Temporal shifts in traits of Vibrio cholerae strains isolated from hospitalized patients in Calcutta: a 3 years (1993 to 1995) analysis. J Clin Microbiol 1996, 34:2537-2543

10. Dalsgaard A, Forslund A, Serichantalergs O, Sandvang D: Distribution and content of class 1 integrons in different Vibrio cholerae O-serotype strains isolated in Thailand. Antimicrob Agents Chemother 2000, 44:1315-1321

11. Waldor MK, Tschäpe H, Mekalanos JJ: A new type of conjugative transposon encodes resistance to sulfamethoxazole, trimethoprim, and streptomycin in Vibrio cholerae 0139. J Bacterio/ 1996, 178:4157-65.

12. Dalsgaard A, Forslund AN, Tam DX, Vinh DX, Cam PD: Cholera in Vietnam: changes in genotypes and emergence of class 1 integrons containing aminoglycoside resistance gene cassettes in Vibrio cholerae 01 strain isolated from 1979 to 1996. J Clin Microbiol 1999, 37:734-741.

13. Dalsgaard A, Forslund A, Sandvang D, Arntzen L, Keddy K: Vibrio cholerae O1 outbreak isolates in Mozambique and South Africa in 1998 are multiple-drug resistant, contain the SXT element and the aadA2 gene located on class 1 integrons. J Antimicrob Chemother 2001, 48:827-838

14. Amita , Chowdhury SR, Thungapathra M, Ramamurthy T, Nair GB, Ghosh A: Class 1 integrons and SXT elements in El Tor strains isolated before, and after 1992 Vibrio cholerae outbreak, Calcutta, India. Emerg Infect 2003, 9:500-502.

15. Mohapatra H, Mohapatra SS, Mantri CK, Colwell RR, Singh DV: Vibrio cholerae non-O1, non-0139 strains isolated before 1992 from Varanasi, India are multiple drug resistant, contain intSXT, dfr 18 and aadA5 genes. Environ Microbiol 2008, 10:866-873.

16. Bhanumathi R, Sabeena F, Isac SR, Shukla BN, Singh DV: Molecular characterization of Vibrio cholerae 0139 Bengal isolated from water and the aquatic plant Eichhornia crassipes in the River Ganga, Varanasi, India. Appl Environ Microbiol 2003, 69:2389-2394

17. Falbo V, Carattoli A, Tosini F, Pezzella C, Dionisi AM, Luzzi I: Antibiotic resistance conferred by a conjugative plasmid and a class I integron in Vibrio cholerae $\mathrm{O} 1 \mathrm{El}$ Tor strains isolated in Albania and Italy. Antimicrob Agents Chemother 1999, 43:693-696.

18. Hochhut B, Lotfi Y, Mazel D, Faruque SM, Woodgate R, Waldor MK Molecular analysis of the antibiotic resistance gene clusters in the Vibrio cholerae 0139 and 01 SXT constins. Antimicrob Agents Chemother 2001, 45:2991-3000.

19. Miyazato T, Tamaki Y, Sithivong N, Phantouamath B, Insisiengmay S, Higa $\mathrm{N}$, Toma C, Nakasone N, Iwanaga M: Antibiotic susceptibility and its genetic analysis of Vibrio cholerae non-O1, non-O139 from environmental sources in Lao People's Democratic Republic. Trop Med Health 2004, 32:245-248.

20. Igbinosa EO, Obi CL, Okoh Al: Occurrence of potentially pathogenic vibrios in the final effluents of a wastewater treatment facility in a rural community of the Eastern Cape Province of South Africa. Res Microbiol 2009, 160:531-537.
21. Igbinosa EO, Okoh Al: Impact of discharged wastewater effluents on the physico-chemical qualities of a receiving watershed in a typical rural community. Int/ J Environ Sci Technol 2009, 6(2):175-182.

22. Odjadjare EEO, Okoh Al: Prevalence and distribution of Listeria pathogens in the final effluents of a rural wastewater treatment facility in the Eastern Cape Province of South Africa. World J Microbiol Biotechnol 2010, 26(2):297-307.

23. Fatoki SO, Gogwana P, Ogunfowokan AO: Pollution assessment in the Keiskamma River and in the impoundment downstream. Water SA 2003, 29(3):183-187

24. Li J, Yie J, Foo WT, Ling, Julia ML, Huaishu X, Norman YS: Antibiotics resistance and plasmid profile of Vibrio isolated from cultured silver sea bream, Sparus sarba. Marine Poll Bull 2003, 39:45-49.

25. Son R, Nasreldine EH, Zaiton H, Samuel L, Rusul G, Nimita F: Characterization of Vibrio vulnificus isolated from cockles (Anadara granosa): antimicrobial resistance, plasmid profile and random amplification of polymorphic DNA analysis. FEMS Microbiol Lett 1998, 165:139-143.

26. Lesmana M, Subekti D, Simanjuntak CH, Tjaniadi P, Campbell JR, Ofoyo BA: Vibrio parahaemolyticus associated with cholera-like diarrhea among patients in North Jajarta, Indonesia. Diagn Microbiol Infect Dis 2001, 39:71-75.

27. French GL, Woo ML, Hui YW, Chan KY: Antimicrobial susceptibility of halophilic vibrios. J Antimicrob Chemother 1989, 24:183-194.

28. Zulkifli Y, Alitheen NB, Raha AR, Yeap SK, Marlina, Son R, Nishibuchi M Antibiotic resistance and plasmid profiling of Vibrio parahaemolyticus isolated from cockles in Padang, Indonesia. Intl Food Res J 2009, 16:53-58.

29. Ramachandran D, Bhanumathi R, Singh DV: Multiplex PCR for detection of antibiotic resistance genes and the SXT element: application in the characterization of Vibrio cholerae. J Med Microbiol 2007, 56:346-351.

30. Thungapathra M, Amita Sinha KK, Chaudhuri SR, Garg P, Ramamurty T, Nair GB, Ghosh A: Occurrence of antibiotic resistance gene cassettes aac(6')-lb, dfrA5, dfrA12, and ereA2 in class 1 integrons in non-O1, non0139 Vibrio cholerae strains in India. Antimicrob Agents Chemother 2002, 46:2948-55.

31. Tabtieng R, Wattanasri S, Echeverria P, Seriwatana J, Bodhidatta L, Chatkaeomorakot A, Rowe B: An epidemic of Vibrio cholerae El Tor Inaba resistant to several antibiotics with a conjugative group $C$ plasmid coding for type II dihydrofolate reductase in Thailand. Am J Trop Med Hyg 1989, 41:680-686

32. Bauer AW, Kirby WMM, Sheris JC, Turck M: Antibiotics susceptibility testing by standardized single disk method. Am J Clin Pathol 1966 45:493-496.

33. Clinical and Laboratory Standards Institute (CLSI): Performance standards for antimicrobial susceptibility testing; fifteenth informational supplement, M100-S15 Volume 25. Issue no 1 Clinical and Laboratory Standards Institute Wayne, Pa; 2005.

34. Maugeri TL, Carbone M, Fera MT, Gugliandolo C: Detection and differentiation of Vibrio vulnificus in seawater and plankton of coastal zone of the Mediterranean Sea. Res Microbio/ 2006, 157:194-200.

35. I wanaga M, Toma C, Miyazato T, Insisiengmay S, Nakasone N, Ehara M: Antibiotic resistance conferred by a class I integron and SXT constin in Vibrio cholerae $\mathrm{O} 1$ strains isolated in Laos. Antimicrob Agents Chemother 2004, 48:2364-2369.

36. Schmidt AS, Bruun MS, Dalsgaard I, Larsen JL: Incidence, distribution, and spread of tetracycline resistance determinants and integronassociated antibiotic resistance genes among motile aeromonads from a fish farming environment. Appl Environ Microbiol 2001, 67:5675-5682

doi: $10.1186 / 1471-2180-10-143$

Cite this article as: Okoh and Igbinosa, Antibiotic susceptibility profiles of some Vibrio strains isolated from wastewater final effluents in a rural community of the Eastern Cape Province of South Africa BMC Microbiology 2010, $10: 143$ 